\title{
LASTARRIA Y SARMIENTO: \\ EL CHILENO Y EL ARGENTINO ACHILENADO
}

\author{
POR \\ NORMAN P. SACKS \\ University of Wisconsin, Madison
}

Cuatro años antes de su muerte, Domingo Faustino Sarmiento (18111888) le escribía a un amigo chileno, antes de partir en su último viaje a Chile: "Chile fue mi teatro y le debo los más gratos recuerdos. Quisiera verla antes de morir, como la primera página y la más bella del libro de la vida» ${ }^{1}$. Fue la última vez que se encontró Sarmiento con Lastarria, «amigo de todas las horas de la vida».

Sarmiento visitó a Chile en varias ocasiones, y vivió en Chile durante dos épocas de su vida: desde 1831 a 1836 y desde 1841 a 1855 . Fue en Chile donde publicó Sarmiento algunas obras suyas más importantes: $M i$ defensa (1843), Facundo (1845), Apuntes biográficos del general fray Félix Aldao (1845), Viajes por Europa, Africa y América (1849), Educación popular (1849), Recuerdos de provincia (1850), Argirópolis (1850), Campaña en el Ejército Grande de Sud América (1852), Educación común (1852) y Comentarios de la Constitución (1853).

En este ensayo vamos a enfocar sobre la época más importante de residencia de Sarmiento en Chile, a saber, la época desde 1841 a 1855, y sobre las relaciones de Sarmiento con el pensador y publicista chileno José Victorino Lastarria (1817-1888).

Discutiendo el movimiento político en Chile del año 1841, escribía Lastarria:

Por aquel tiempo estaba ya entre nosotros la brillante emigración arjentina que habían lanzado a este lado de los Andes la tiranía de Rosas i de sus aliados, los caudillos de provincia, i la sangrienta guerra civil

Armando Donoso, «Sarmiento en Chile», en Revisia de Filosofía, año 7 (1921), pp. 203-204. 
que había terminado con la ruina de Lavalle, de Paz i de los demás jefes unitarios que habían sucumbido por libertar a su patria ${ }^{2}$.

Sarmiento era uno de esos emigrados argentinos, y Lastarria nos ha dejado su primera impresión del argentino:

El hombre realmente era raro: sus treinta $i$ dos años de edad parecian sesenta, por su calvo frente, sus mejillas carnosas, sueltas i afeitadas, su mirada fija pero osada, a pesar del apagado brillo de sus ojos, $\mathrm{i}$ por todo el conjunto de su cabeza, que reposaba en un tronco obeso i casi encorbado. Pero eran tales la viveza i la franqueza de la palabra de aquel joven viejo, que su fisonomía se animaba con los destellos de un gran espíritu, i se hacia simpática e interesante. Despues de hablarnos de su última campaña, de su derrota con el jeneral La Madrid, de un paso por los Andes, donde estuvo a punto de perecer con todos sus compañeros, por una larga i copiosa nevada, que los sitió en la casilla de las Cuevas, nos habló con el talento i la esperiencia de un institutor mui pensador, sobre instruccion primaria, porque aquel hombre tan singular era Domingo Faustino Sarmiento, el entónces maestro de escuela i soldado en los campos de batalla contra la tiranía de Rosas, el formidable diarista, al poco tiempo despues, el futuro presidente de la República Arjentina... Tanto nos interesó aquel embrión de grande hombre, que tenia el talento de embellecer con la palabra sus formas casi de gaucho, que pronto nos intimamos con él; habiéndole indicado que abriese una escuela para ganar su vida, le ayudamos a fundarla en aquellos mismos departamentos solitarios del tercer piso de los portales, comenzando desde entónces a allanarle el camino para la direccion de la escuela normal de preceptores, que tenia en proyecto don Manuel Montt, quien era a la sazon el ministro que servia de centro a las esperanzas de todos los que anhelábamos por un cambio de política, i por una proteccion mas intelijente i mas decidida a la instruccion pública. Poco despues le presentamos en casa de aquel ministro, dando así oríjen a una larga amistad, que hoi mantienen ambos, despues de habérsela comprobado con recíprocos servicios ${ }^{3}$.

En esta larga cita de Lastarria se pueden notar varios aspectos importantes de las actividades subsiguientes de Sarmiento en Chile: su actividad como maestro de escuela; periodista y soldado en la lucha contra la tiranía de Juan Manuel de Rosas en la Argentina; director de la Escuela Normal, y la amistad de Sarmiento y Manuel Montt, que era ministro de

${ }^{2}$ Recuerdos literarios, 2. ${ }^{a}$ ed. (Santiago de Chile: Librería de M. Servat, 1885), p. 81 .

${ }^{3}$ Ibid., pp. $81-82$. 
la Instrucción Pública y que 1legó a ser presidente de la República de Chile, con el fuerte apoyo de Sarmiento.

Era precaria la situación de Sarmiento cuando lo conoció Lastarria en los primeros días de enero de 1841 . No tenía dinero, pero sí tenía aptitud para la enseñanza y una capacidad literaria. Le interesaba mucho el periodismo, y, estimulado por sus nuevos amigos, Sarmiento escribió un artículo sobre la batalla de Chacabuco, cuyo aniversario se acercaba. Lastarria, que leyó el artículo y lo consideró digno de publicarse, lo envió a Manuel Rivadeneyra, propietario de El Mercurio de Valparaíso y el futuro editor de la importante colección conocida como la «Biblioteca de Autores Españoles» (BAE). En El Mercurio fue publicado el artículo el 11 de febrero, con el título: «12 de febrero de $1817 »$. Sarmiento lo firmó con el seudónimo: un teniente de artillería en Chacabuco ${ }^{4}$.

Sarmiento recuerda sus emociones del día de la publicación de su artículo:

Los que han recibido una educación ordenada, asistido a las aulas, rendido exámenes, sentídose fuertes por la adquisición de diplomas de capacidad, no pueden juizgar de las emociones de novedad, de pavor, de esperanza y de miedo que me agitaban al lanzar mi primer escrito en la prensa de Chile. Si me hubiese preguntado a mí mismo entonces si sabía algo de política, de literatura, de economía y de crítica, habríame respondido francamente que no... Bajo el aguijón de la duda... aguardé la llegada de El Mercurio del 11 de febrero de $1841 \ldots$ Un solo amigo estaba en el secreto; yo permanecía en casa escondido de miedo. A las once trájome buenas noticias: $\mathrm{mi}$ artículo había sido aplaudido por los argentinos; esto era ya algo. A la tarde se hablaba de él en los corrillos, a la noche en el teatro; al día siguiente supe que don Andrés Bello y [Mariano] Egaña lo habían leído juntos, hallándolo bueno. ¡Dios sea loado!, me decía a mí mismo; estoy ya a salvo ${ }^{5}$.

En la reacción de Sarmiento a la publicación de su artículo se advierte que Sarmiento era autodidacto. Exa de familia pobre, y aunque sus padres reconocían en él una fuerte inteligencia y querían conseguir para él una instrucción secundaria, la única escuela a que asistió el niño Sarmiento fue una escuela primaria, la «Escuela de la Patria». El programa de esta escuela comprendía: «Lectura, Escritura, Doctrina cristiana, Nociones de Aritmética y de Gramática, Ortografía, Aritmética comercial,

\footnotetext{
"José Guillermo Guerra, Sarmiento: su vida y sus obras (Santiago de Chile: Imprenta Universitaria, 1938), p. 64.

${ }^{5}$ D. F. Sarmiento, Recuerdos de provincia, en Obras completas de Sarmiento (Buenos Aires: Editorial Luz del Día, 1948), t. III, pp. 193-194.
} 
Historia sagrada, repartidos en tres cursos, y Algebra» ${ }^{6}$. Sin embargo, Sarmiento, desde niño, fue «un devorador de libros».

En contraste con Sarmiento, Lastarria tenía la ventaja de una preparación sistemática. Gracias a una beca del presidente Francisco Antonio Pinto, político pipiolo o liberal, Lastarria, a los doce años, ingresó en el Liceo de Chile, un colegio de segunda enseñanza, fundado y dirigido por el liberal español José Joaquín de Mora. Además de contar con excelentes profesores, «los métodos de estudios eran serios i eficaces a proporcionar a los educandos una sólida i jeneral instrucccion», dice el biógrafo de Lastarria, Alejandro Fuenzalida Grandón ${ }^{7}$.

En el Liceo de Chile estudió Lastarria cursos de Literatura española, de Gramática latina, francesa y castellana; de Filosofía, de Geografía y de Liberalismo (con Mora). Su profesor principal fue el director Mora, que ejerció sobre el adolescente Lastarria una profunda influencia.

Después de la violenta clausura del Liceo de Chile y el destierro de Mora, por orden del ministro omnipotente Diego Portales, Lastarria, que tenía catorce años, continuó su educación en el Instituto Nacional, fundado en 1813, y el único centro de instrucción general (inclusive de instrucción a nivel universitario) en Chile en esa época. El Instituto Nacional había adoptado muchas de las ideas que se hallaban en el plan de estudios del Liceo de Chile. Lastarria estudió en los cursos siguientes, todos obligatorios: Historia, Geografía, Literatura, Gramática castellana, Francés, Derecho natural, Derecho de gentes y Economía política ${ }^{8}$. Además de los cursos enumerados aquí, Lastarria estudió Latín, Inglés, Física y Filosofía.

Lastarria era discípulo de Andrés Bello en 1834. En casa del gran humanista, Lastarria atendió a cursos de gramática, literatura, español y derecho romano. Cuarenta años después, Lastarria juzgó el carácter de la enseñanza de su distinguido maestro:

La enseñanza de aquellos ramos era vasta $i$ comprensiva, bien que adolecía de cierta estrechez de método, de la cual todavía no había podido emanciparse el maestro, obedeciendo a las influencias de la época en que él se educara. El estudio de la lengua era un curso completo de filolojía, que comprendia desde la gramática jeneral i la historia del castellano, hasta las mas minuciosas cuestiones de la gramática de este idioma... Pero el señor Bello era sumamente serio, impasible i terco.

${ }^{6}$ Guerra, op. cit., p. 19.

- Lastarria i su tiempo: su vida, obras e influencia en el desarrollo político e intelectual de Chile (Santiago de Chile: Imprenta, Litografía i Encuadernación Barcelona, 1911), t. I, p. 19.

- Joaquín Rodríguez Bravo, Don José Victorino Lastarria (Santiago de Chile: Imprenta Barcelona, 1892), p. 15. 
Nunca esplicaba, sólo conversaba, principiando siempre por esponer una cuestion, para hacer discurrir sobre ella a sus discípulos... Las cuestiones de derecho eran debatidas largamente, hasta que se examinaban todos los detalles, todos los casos de cada una. Mas, esta manera de hacer estudiar a los alumnos, que tan provechosa puede ser con una direc. cion filosófica, perdia toda su utilidad con aquel método fundado en la enseñanza de los detalles, bueno sin duda para formar abogados casuistas i literatos sin arte ${ }^{9}$.

En diciembre de 1836, Lastarria recibió el grado de Bachiller en la Facultad de Leyes y Ciencias Canónicas de la antigua Universidad de San Felipe. Poco después fue admitido a la Academia de Leyes y Práctica Forense «para hacer, durante los dos años exigidos por los reglamentos escolares, su práctica en la tramitación de los juicios» ${ }^{10}$. El gran interés de Lastarria en el Derecho se refleja en algunos tomos de sus Obras completas, que consisten en estudios constitucionales, estudios jurídicos y proyectos de ley.

Cuando se comparan las actividades de los dos hombres en la enseñanza, se puede decir que Sarmiento era, esencialmente, maestro de escuela y que Lastarria tenía carrera en el profesorado.

En 1831, durante otra época de residencia de Sarmiento en Chile, el argentino fue nombrado maestro de la escuela municipal en Santa Rosa de los Andes. La escuela era un plantel humilde. El local era una pieza, y los ramos de estudio eran la lectura, escritura y primeras reglas de la Aritmética ${ }^{11}$.

En 1842, cuando fue nombrado director de la Escuela Normal de Preceptores, Sarmiento tuvo a su cargo clases de Lectura, Gramática, Geografía, Aritmética y Cosmografía. Y cuando se inauguró la Universidad de Chile, en 1843, fue nombrado miembro de la Facultad de Filosofía y Humanidades.

En 1836, a la edad de diecinueve años, Lastarria daba clases de Literatura en el Colegio de las Hermanas Cabezón y enseñaba Geografía en el Colegio del Presbítero Romo. Dos años después enseñaba Derecho de gentes, Ortología y Geografía universal en el Colegio de Romo. A causa de la falta de textos elementales apropiados para la enseñanza, Lastarria, siguiendo el ejemplo de Andrés Bello, publicó, en 1838, sus Lecciones de Geografía moderna, uel primer texto en que se ha dado en Chile noticias completas sobre la materia» ${ }^{12}$. Hubo numerosas reimpresiones de este

\footnotetext{
${ }^{9}$ Recuerdos literarios, pp. 65-66.

10 Rodríguez Bravo, op. cit., p. 31.

"Guerra, op. cit., p. 44.

${ }^{12}$ Fuenzalida Grandón, op. cit., t. I, p. 32.
} 
libro y fue adoptado como libro de texto en Chile y en otros países sudamericanos. En 1841, Lastarria fue nombrado director del Colegio de Romo.

En 1839, Lastarria fue nombrado profesor de Legislación y Derecho de gentes en el Instituto Nacional, y desemepeñó ese puesto por cerca de tres lustros. En el Instituto, Lastarria enseñaba a sus alumnos los principios del Derecho; estableció en Chile la enseñanza del Derecho constitucional, y en 1846, cuando Lastarria era profesor en el Instituto Nacional y en la Universidad de Chile, publicó un libro de texto titulado Elementos de Derecho público constitucional (arreglados i adoptados a la enseñanza de la juventud americana). La Universidad aprobó este libro como texto de enseñanza. Y, también en 1846, propuso Lastarria un plan a la Facultad de Leyes, recomendando varias reformas en la enseñanza del Derecho. En su Introducción al primer tomo de las Obras completas de Lastarria (tomo que contiene Elementos de Derecho público constitucional, con su título completo, es decir, Elementos de Derecho público constitucional, teórico filosófico, positivo i político), Fuenzalida Grandón dice: «La especialidad del señor don José Victorino Lastarria es la Ciencia política.»

Lastarria fue nombrado miembro de la Facultad de Filosofía y Humanidades de la Universidad de Chile en 1843 y también miembro de la Facultad de Leyes y Ciencias Políticas (la Universidad tenía cinco Facultades. Las otras tres eran: Ciencias matemáticas y físicas, Medicina y Teología). En 1860, Lastarria fue elegido decano de la Facultad de Humanidades durante dos períodos consecutivos. En su decanato, Lastarria deseaba hacer honor a dos de sus maestros. En 1861, con la recomendación de Lastarria, José Joaquín de Mora fue designado miembro honorario corresponal de la Facultad de la Universidad de Chile. Y en 1862 recomendó Lastarria que se publicara, «a costa del Estado i bajo la protección de la Universidad», una obra importante inédita de Andrés Bello sobre el Poema del Cid, y la recomendación de Lastarria fue aprobada por el Gobierno.

Entre los libros de texto que escribió Lastarria hay uno que alcanzó gran éxito: Lecciones de politica positiva. Publicado en 1874, este libro tenía por objeto «dar la verdadera doctrina científica sobre la teoría de la sociedad civil $\mathbf{i}$ sobre la organizacion política» ${ }^{13}$. Este libro era, en gran parte, una síntesis de las ideas de Augusto Comte, pero con modificaciones. Lastarria no aceptó la religión de la Humanidad, que fue parte del sistema positivo de Comte. Esta obra fue traducida al francés y al

${ }^{13}$ Fuenzalida Grandón, op. cit,, t. II, p. 42. 
portugués y fue adoptada como texto oficial en universidades de otros países, p. ej., en México y en el Brasil. Sobre Lecciones de política positiva ha dicho Fuenzalida Grandón: «La aparición de las Lecciones de política positiva puede considerarse como un verdadero acontecimiento político i literario. Hasta 1874 nadie habia publicado nada en Chile sobre la materia» ${ }^{14}$.

En resumen, se puede decir que Sarmiento era maestro de escuela y maestro de maestros; Lastarria, aparte de su carrera en el profesorado, era básicamente un pensador político, y su orientación política es evidente hasta en sus obras literarias ${ }^{15}$.

«Sarmiento entró a Chile como un ventarrón: golpeando puertas, rompiendo vidrios, despertando a las gentes de su sueño», escribió Aníbal Ponce ${ }^{16}$. En un tiempo relativamente corto, después de la publicación de su artículo sobre la batalla de Chacabuco en El Mercurio de Valparaíso, Sarmiento se vio envuelto en la vida política, educacional y cultural de Chile, participando en luchas políticas y en muchas ruidosas polémicas. Por sus actividades periodísticas, Sarmiento se hizo divulgador de ideas políticas, literarias y sociales no solamente del Viejo Mundo, sino también de toda América ${ }^{17}$.

Como resultado de la impresión favorable que produjo su primer artículo en El Mercurio (único diario chileno entonces, fundado en 1827), el editor ofreció a Sarmiento la redacción del diario. Sarmiento aceptó el puesto y así comenzó su carrera de periodista en Chile. Hay que tener presente que $E l$ Mercurio, para vivir, necesitaba una subvención del Gobierno, y por eso era un órgano semioficial de la política dominante, es decir, del Partido Conservador ${ }^{18}$.

Sarmiento estuvo en Chile durante el período que los historiadores chilenos llaman «la República autoritaria» o «la República autocrática». El Partido Pelucón o Conservador había sido reorganizado y dirigido por Diego Portales, después del triunfo de los conservadores en la revolución de 1829. Esta República, dominada por los conservadores, abarcó los decenios de las presidencias del general Joaquín Prieto (1831-41), del gene-

${ }_{14}$ Ibid., p. 45.

${ }^{15}$ Véase Bernardo Subercaseaux, Cultura y sociedad liberal en el siglo XIX: Lastarria (ideología y literatura) (Santiago de Chile: Editorial Aconcagua, 1979), passim.

${ }^{16}$ Aníbal Ponce, Sarmiento, constructor de la nueva Argentina (Madrid: EspasaCalpe, 1932), p. 78.

${ }_{17}$ Ricardo A. Latcham, "Sarmiento, periodista y costumbrista», en Latcham, $A n^{-}$ tología: Crónica de varia lección. Selección y prólogo de Alfonso Calderón y Pedro Lastra (Santiago de Chile: Empresa Editora Zig-Zag, 1965), p. 179.

${ }^{18}$ Guerra, op. cit., p. 65. 
ral Manuel Bulnes (1841-51), y de don Manuel Montt, el heredero de la tradición portaliana (1851-61) ${ }^{19}$.

En 1841, la presidencia del general Prieto debía expirar, y el candidato del Partido Pelucón era el general Manuel Bulnes, vencedor en la guerra contra la Confederación Peruano-Boliviana, «el héroe de Yungay». El candidato de los pipiolos o liberales era el antiguo presidente (18271829) Francisco Antonio Pinto, que había sido elegido vicepresidente de la República, y que, por renuncia del presidente Freire, ocupó la presidencia.

El Partido Conservador tenía un periódico que había de servir como órgano de sus ideas. Manuel Montt, joven de treinta y dos años, ministro de Instrucción Pública y político prominente del Partido Conservador, estaba muy impresionado por los artículos de Sarmiento aparecidos en $E l$ Mercurio, y pidió al argentino que trabajara como redactor de El Nacional, el periódico que había de apoyar la candidatura de Bulnes. Mientras tanto, Lastarria, junto con Pedro Ugarte, fundó otro diario, El Miliciano, para apoyar la candidatura del general Pinto, «a quien juzgaba [Lastarria] como un verdadero representante del sistema liberal». El general Las Heras, uno de los distinguidos emigrados argentinos en Chile, y de gran ayuda para Sarmiento, solicitó a éste que apoyara al general Pinto y la causa de los pipiolos. Sarmiento meditó ocho días y se decidió a apoyar la causa de los pelucones ${ }^{20}$. Al hacerlo, explicó su decisión con las siguientes palabras:

Pedí ocho días para responder, y en esos ocho días medité mucho, estudié a ojo de pájaro los partidos de Chile, y saqué en limpio una verdad que confirmaron las elecciones de 1841, a saber, que el antiguo partido pipiolo no tenía elementos de triunfo, que era una tradición y no un hecho... Pasados los ocho días reuní a varios argentinos, cuya opinión respetaba..., y les pedí su parecer. En cuanto a mi carácter de argentino había otras consideraciones de más peso que tener presentes. Estábamos acusados por el tirano de nuestra patria de perturbadores, sediciosos y anarquistas, y en Chile podían tomarnos por tales, viéndonos en oposición siempre a los gobiernos. Necesitábamos, por el contrario, probar a la América, que no eran utopías lo que nos hacía sufrir la persecución, y que dada la imperfección de los gobiernos americanos, estábamos dispuestos a aceptarlos como hechos, con ánimo decidido, yo al menos, de inyectarles ideas de progreso; últimamente, que estando para decidirse por las elecciones el rumbo que tomaría la política en

${ }^{19}$ Luis Galdames, Historia de Chile, 11. ${ }^{\mathrm{a}}$ ed. (Santiago de Chile: Empresa Editora Zig-Zag, 1946), caps. XIV y XV.

${ }_{20}$ Guerra, op. cit., pp. 65-66; Fuenzalida Grandón, op. cit., t. I, pp. 52-53. 
Chile, sería fatal para nuestra causa habernos concitado la animadversión del partido que gobernaba en aquel momento, si triunfaba, como era mi convicción íntima que debía suceder... apoyado en el asentimiento de mis compatriotas, me negué a la solicitud de los liberales chilenos ${ }^{21}$.

La decisión de Sarmiento de apoyar a los conservadores era muy importante para su futuro en Chile. Al mismo tiempo, esa decisión marcó el principio de una serie de sucesos políticos que habían de afectar las relaciones amistosas entre Lastarria y Sarmiento.

El annus mirabilis del desarrollo cultural de Chile es 1842. Fue el año de la famosa polémica sobre el clasicismo y el romanticismo, en la que tomaban parte Andrés Bello y Domingo F. Sarmiento. «El mismo año -1842 - dio su nombre a un nuevo movimiento y a una nueva generación. Los críticos literarios se refieren al 'movimiento literario de 1842', en tanto que los historiadores hablan a veces del 'movimiento político de 1842'. De todos modos, el movimiento era intelectual y cultural en el sentido más amplio de la palabra, y en el siglo xix, cuando la mayor parte de los hombres de letras de Chile dividían sus vidas entre la política y las letras, y las obras de literatura servían a menudo un propósito político, un movimiento literario apenas podía evitar la participación en la política» ${ }^{22}$.

Los dos principales maestros de la generación de 1842 fueron José Joaquín de Mora y Andrés Bello, los dos, como hemos visto, profesores de Lastarria. Hubo tres refugiados hispanoamericanos que vivieron en Chile en esa época y que hicieron contribuciones importantes a la formación intelectual de la generación de 1842: el colombiano Juan García del Río y los argentinos Domingo Faustino Sarmiento y Vicente Fidel López. Los emigrados argentinos eran arrogantes y acusaban a los jóvenes chilenos de esterilidad literaria. Sarmiento analiza las causas de esta esterilidad y, al mismo tiempo, of rece consejos a los chilenos:

Es la perversidad de los estudios que se hacen, el influjo de los gramáticos, el respeto a los admirables modelos, el temor de infringir las reglas, lo que tiene agarrotada la imaginación de los chilenos, lo que hace desperdiciar bellas disposiciones y alientos generosos. No hay espontaneidad, hay una cárcel cuya puerta está guardada por el inflexible culteranismo, que da sin piedad de culatazos al infeliz que se le presenta

${ }^{21}$ Recuerdos de provincia, en Obras completas de Sarmiento, t. III, p. 195.

${ }^{22}$ Norman P. Sacks, "José Victorino Lastarria: un intelectual comprometido en la América Latina», en Revista chilena de historia y geografía, 140 (1972), pp. 161-162. 
en toda forma. Pero cambiad de estudios y en lugar de ocuparos de las formas, de la pureza de las palabras, de lo redondeado de las frases, de lo que dijo Cervantes o fray Luis de León, adquirid ideas, de donde quiera que vengan, nutrid vuestro pensamiento con las manifestaciones del pensamiento de los grandes luminares de la época; y cuando sintais que vuestro pensamiento a su vez se despierta, echad miradas observadoras sobre vuestra patria, sobre el pueblo, las costumbres, las instituciones, las necesidades actuales y en seguida escribid con amor, con corazón lo que se os alcance, lo que se os antoje, que eso será bueno en el fondo, aunque la forma sea incorrecta; será apasionado, aunque a veces sea inexacto; agradará al lector, aunque rabie Garcilaso; no se parecerá a lo de nadie; pero bueno o malo, será vuestro, nadie os lo disputará 23 .

Muchos años después, Lastarria recuerda así a los emigrados argentinos de esa época:

Esta era nuestra situacion en los momentos en que llegaba a apoderarse de la prensa i del movimiento intelectual, aquella brillante emigracion arjentina, en que al lado del profundo espíritu filosófico de Vicente Fidel López, campeaba el talento osado i batallador de Sarmiento; i en que el sutil i correcto injenio de Alberdi, i la elevada i vasta erudicion literaria de Juan María Gutiérrez figuraban i se hacian notar aun en la penumbra de aquella constelación de noveles $i$ bulliciosos escritores, que aspiraban a eclipsarlo todo. Esos espíritus del Plata, eléctricos i deslumbrantes como los rayos de su cielo tempestuoso, habian tenido otra direccion $\mathrm{i}$ se habian disciplinado en una lucha de libertad. Los mas circunspectos de ellos se admiraron al conocer nuestra educación, a la par de que los mas ardientes se rieron de ella i nos trataron de ignorantes $\mathrm{i}$ atrasados. Unos i otros hacian poco caso de la forma. Lo daban todo al pensamiento, i prescindiendo de la gramática i de la retórica, buscaban el arte literario solo en la idea, i no en su manifestacion sensible, cual si la idea pudiera aparecer en toda su luz i bajo una forma artística, cuando se la representa de una manera impropia i arbitraria ${ }^{24}$.

Sarmiento estimaba mucho a Lastarria. En un artículo titulado «Repartición de premios en el Instituto Nacional», publicado el 9 de marzo de 1842 en $E l$ Mercurio, Sarmiento discute la distribución de premios

${ }^{23}$ Citado por Armando Donoso, Samiento en el destierro (Buenos Aires: Gleizer, 1927), pp. 17-18.

${ }^{24}$ «Recuerdos del maestro», en Obras completas de don J. V. Lastarria (Santiago de Chile: Imprenta, Litografía i Encuadernación Barcelona, 1913), t. XI, pp. 97-98. Este artículo fue publicado en la Suscripción de la Academia de Bellas Letras a la estatua de don Andrés Bello (Santiago de Chile, 1874). 
hecha por los profesores del Instituto Nacional en un acto presidido por el ministro de Instrucción Pública, don Manuel Montt. Lastarria pronunció un discurso que le gustó mucho a Sarmiento:

El señor don Victorino Lastarria pronunció tambien una oracion que escitó el mas profundo interes en el público, tanto por lo luminoso de su esposicion, el brillo de las imájenes i la elevacion de los conceptos, como por las ideas que desenvolvió, en que hizo sentir de la manera mas animada la influencia que los trabajos de los alumnos ejercerian en la suerte futura de su patria; lo que era hoi el imperio de la intelijencia $i$ el alto papel que estaban llamados a hacer en el porvenir. Este discurso ha merecido los mas altos elojios de las personas intelijentes $i$ ha labrado al señor Lastarria un título mas a la estimacion de sus conciudadanos ${ }^{25}$.

Ante el desahogo de Sarmiento, los jóvenes de Santiago se deciden a formar una asociación literaria. Esta asociación se llamó la «Sociedad Literaria». Tiene unos cuarenta miembros, y la mayor parte son alumnos del curso de Legislación del Instituto Nacional. La «Sociedad Literaria» se reúne ochenta y seis veces, desde el 5 de marzo de 1842 hasta el 1 de agosto de 1843. Lastarria se incorpora a la «Sociedad» el 3 de mayo, y es elegido director ${ }^{26}$.

Sarmiento había llamado la atención sobre la pobreza del diarismo chileno, y como reacción a su crítica, un grupo de jóvenes chilenos, encabezado por Lastarria, fundó El Semanario de Santiago, que aspiró a ser el órgano de los intelectuales chilenos y que funcionó también como el órgano de la «Sociedad Literaria». Algunos redactores de El Semanario eran también miembros de la «Sociedad Literaria». Sarmiento comentó muy favorablemente la aparición de El Semanario de Santiago. Creía que el periódico podría trabajar en pro de la cultura chilena ${ }^{27}$.

Lastarria, como dice el crítico Ricardo Latcham, era el alma del movimiento de 1842. El fue el fundador principal y director de la «Sociedad Literaria», que había de ser el centro de las nuevas ideas que resultarían en la regeneración cultural e intelectual de Chile. El fue el fundador principal de la revista El Seminario de Santiago y fue él quien inauguró formalmente la «Sociedad Literaria», y con ella, la nueva generación, con su famoso Discurso inaugural del 3 de mayo de 1842. Lastarria contaba a la sazón con veinticinco años de edad, y ya entonces deseaba que se estableciera una literatura nacional, independiente de la literatura españo-

${ }^{25}$ Obras completas de Sarmiento, t. I, p. 182.

${ }^{26}$ Norberto Pinilla, La generación chilena de 1842 (Santiago de Chile: Ediciones de la Universidad de Chile, 1943), pp. 105-113.

${ }^{27}$ Ibid., pp. 126-134. 
la o de cualquier otra. En su discurso se destacan varios temas predilectos, que figuran en otros escritos suyos: la necesidad de la democracia y la identificación de ésta con la libertad, la literatura es la expresión de la sociedad, su fe en la ley del progreso, la necesidad de rechazar el pasado colonial español, la hermosura del idioma español, la necesidad de emancipar la literatura de las rigurosas y mezquinas reglas, etc. ${ }^{28} \mathrm{El}$ Discurso inaugural de Lastarria, que tuvo gran resonancia, fue recibido con aplauso por Sarmiento ${ }^{29}$.

Unos meses antes de la formación de la «Sociedad Literaria» hubo un acontecimiento de gran importancia educacional y social para Chile: el decreto del 18 de enero de 1842, por Manuel Montt, ministro de Instrucción Pública, que estableció la Escuela Normal de Preceptores. Los dos primeros artículos del decreto son los siguientes: «Se establecerá en Santiago una Escuela Normal para la enseñanza e instrucción de las personas que han de dirigir las escuelas primarias en toda la extensión de la República. En esta escuela se enseñarán los ramos siguientes: leer y escribir con perfección y un conocimiento completo de los métodos de enseñanza mutua y simultánea; Dogma moral y religiosa; Aritmética comercial; Gramática y ortografía castellana; Geografía descriptiva; Dibujo lineal; Nociones generales de Historia y particulares de la de Chile» ${ }^{30}$.

Sarmiento fue nombrado por Montt director de la Escuela Normal, que fue la primera de su género en Latinoamérica. El distinguido historiador chileno Ricardo Donoso ha comentado la filosofía de Sarmiento con respecto a la enseñanza:

Hasta entonces la enseñanza había sido una prerrogativa de las clases acaudaladas, y Sarmiento creía que la enseñanza debía ser para todos, de modo que en el fondo de su pensamiento hay - repito- un ideal democrático. Esa idea de fomentar la primera enseñanza y de desarrollarla en todas las clases de la sociedad abría las puertas de la escuela a todo el pueblo para mejorar sus condiciones intelectuales, morales y sociales. Tiene, pues, un profundo sentido político ${ }^{31}$.

${ }^{28}$ Sacks, op. cit., pp. 163-164.

${ }^{29}$ El Discurso inaugural de Lastarria está incluido en sus Recuerdos literarios, pp. 96-115, y en su Miscelánea histórica $i$ literaria (Valparaíso: Imprenta La Patria, 1868), t. II, pp. 5-27. Se puede leer también en Julio Durán Cerda (ed.), El movimiento literario de 1842 (Santiago de Chile: Editorial Universitaria, 1957), t. I, pp. 13-27.

30 Ministerio de Educación Pública, Sarmiento: Director de la Escuela Normal (1842-1845) (Santiago de Chile: Imprenta Universitaria, 1942), p. 10.

${ }^{31}$ «La labor educativa y literaria de Sarmiento en Chile», en Revista Universida des, 4 (Buenos Aires: Unión de Universidades de América Latina, 1961), separata de $16 \mathrm{pp}$. 
Sarmiento fue innovador, y en la enseñanza de la Gramática y de la Lectura cambió los métodos y textos que se usaban en Chile en aquel tiempo. Claro que Sarmiento encontró fuerte oposición a sus ideas y a sus cambios pedagógicos.

En materia de Lengua y de Gramática, las ideas de Sarmiento estaban en abierta oposición con las de Bello. Decía don Andrés: «En las lenguas como en la política, es indispensable que haya un cuerpo de sabios, que así dicte las leyes convenientes a sus necesidades, como las del habla en que ha de expresarlas, y no sería menos ridículo confiar al pueblo la decisión de sus leyes que autorizarle en la formación del idioma» ${ }^{32}$. Sarmiento tenía opinión contraria: «La soberanía del pueblo tiene todo su valor y su predominio en el idioma; los gramáticos son como el Senado conservador, creado para resistir a los embates populares, para conservar la rutina y las tradiciones. Son, a nuestro juicio, si nos perdonan la mala palabra, el partido retrógrado, estacionario, de la sociedad habladora» ${ }^{33}$.

Los emigrados argentinos, sobre todo los agitadores principales, Sarmiento y López, iniciaron el movimiento romántico en Chile. Aprendieron su romanticismo en autores franceses, como Hugo y Lamartine. Por eso su romanticismo era tanto literario como social. Sarmiento y sus colegas escribían artículos para El Mercurio de Valparaíso; Bello y sus discípulos escribían artículos para el Semanario Literario. En 1842 se encendió una polémica entre los dos periódicos y los dos paladines: Sarmiento, el defensor del romanticismo, y Bello, que aparecía como el defensor del clasicismo. Esa polémica sacudió la vida literaria chilena ${ }^{34}$.

Aunque Bello comprendía el romanticismo, por haber vivido muchos años en Inglaterra antes de venir a Chile, en 1829, se dedició a resistir a los refugiados argentinos. En realidad, Bello era clasicista, pero no extremista, y en algunos aspectos no era hostil al romanticismo. La siguiente declaración de Bello ilustra su actitud literaria y política:

En liieratura, los clásicos y románticos tienen cierta semejanza no lejana con lo que son en la política los legitimistas y los liberales. Mientras para los primeros es inapelable la autoridad de las doctrinas y prácticas que llevan el sello de la antigüedad y el dar un paso fuera de aquellos trillados senderos es rebelarse contra los sanos principios, los

${ }^{32}$ «Ejercicios populares de lengua castellana», en El Mercurio (Valparaíso, 12 de mayo de 1842). Citado por Norberto Pinilla, La controversia filológica de 1842 (Santiago de Chile: Prensas de la Universidad de Chile, 1945), p. 28.

${ }^{33}$ "Ejercicios populares de lengua castellana», en El Mercurio (Valparaíso, 27 de abril de 1842). Citado por Pinilla, La controversia filológica de 1842, p. 3.

${ }^{34}$ Enrique Anderson-Imbert, Historia de la literatura hispanoamericana (México, D. F.: Fondo de Cultura Econónica, 1954), t. I, pp. 99, 130. 
segundos, en su conato a emancipar el ingenio de trabas inútiles, y por lo mismo perniciosas, confunden a veces la libertad con la más desenfrenada licencia. La escuela clásica divide y separa los géneros con el mismo cuidado que la secta legitimista las varias jerarquías sociales... La escuela romántica, por el contrario, hace gala de acercar y confundir las condiciones... Pudiera llevarse mucho más allá este paralelo... Pero lo más notable es la natural alianza del legitimismo literario con el político. La poesía romántica es de alcurnia inglesa, como el gobierno representativo, y el juicio por jurados. Sus irrupciones han sido simultáneas con las de la democracia en los pueblos del mediodía de Europa. $\mathrm{Y}$ los mismos escritores que han lidiado contra el progreso en materias de legislación y de gobierno, han sustentado no pocas veces la lucha contra la nueva revolución literaria... ${ }^{35}$

$Y$ en su discurso pronunciado al instalarse la Universidad de Chile, el 17 de septiembre de 1843, el primer rector de la Universidad concluía:

Yo no encuentro el arte en los preceptos estériles de la escuela, en las inexorables unidades, en la muralla de bronce entre los diferentes estilos y gêneros, en las cadenas con que se ha querido aprisionar al poeta a nombre de Aristóteles y Horacio, y atribuyéndoles a veces lo que jamás pensaron. (...) creo que hay un arte que guía a la imaginación en sus más fogosos transportes. Esta es mi fe literaria. Libertad en todo; pero yo no veo libertad, sino embriaguez licenciosa, en las orgías de la imaginación ${ }^{36}$.

Al retirarse Bello de la polémica, triunfaron los defensores del romanticismo. Hubo chilenos que no aceptaron la nueva doctrina, pero la polémica terminó cuando Lastarria se convirtió al romanticismo: «La revolución literaria iniciada en Francia en 1830, esa revolución, proclamada por Victor Hugo con la fórmula de "La libertad en el arte", apenas era aquí conocida por unos cuantos, y había dado ocasion en 1842 a polémicas ardientes con los escritores arjentinos, que la comprendian mejor que nosotros» ${ }^{37}$.

La polémica sobre el romanticismo comenzó sobre cuestiones de Len-

${ }^{35}$ «Juicio crítico de don José Gómez Hermosilla», en tomo VII de la edición chilena de las Obras completas de Andrés Bello (1881-1893), p. 265. Este artículo se publicó en El Araucano (1842). Véase también Germán Arciniegas, El pensamiento vivo de Andrés Bello (Buenos Aires: Losada, 1946), pp. 37-38. Véase, en especial, Emir Rodríguez Monegal, El otro Andrés Bello (Caracas: Monte Avila, 1969), pp. 72-74, 77-78, 206-209, 239-241.

${ }^{36}$ Durán Cerda (ed.), op. cit., t. I, p. 82.

${ }^{37}$ Miscelánea histórica i literaria, pp. vI-vrr. 
gua y de Gramática. Aparte de la lucha ideológica, se cambiaban insultos personales. Lastarria, «que había comenzado combatiendo a Sarmiento desde $E l$ Semanario, acabó por ser su mejor amigo y su más leal aliado» ${ }^{38}$.

La Universidad de Chile se inauguró el 17 de septiembre de 1843. El 17 de octubre, la Facultad de Filosofía y Humanidades (de la que era miembro Sarmiento) celebraba su primera sesión, y Sarmiento presentó el primer trabajo producido por la Universidad, es decir, su Memoria sobre Ortografía americana. Como resultado de su experiencia en la enseñanza primaria y como director de la Escuela Normal, Sarmiento observaba las dificultades causadas por las discordancias de la Ortografía con la pronunciación para los que aprendían a leer. Creía que la Ortografía debía conformarse con la pronunciación y no con la etimología de las palabras. (En España ha existido una larga tradición de reforma ortográfica, comenzando con Antonio de Nebrija a fines del siglo Xv.)

En su Memoria, Sarmiento examinaba el sistema ortográfico de la Real Academia Española y las reformas propuestas por Bello y otros. Declarando que la Ortografía debe fundarse sólo en la pronunciación de las palabras, hizo Sarmiento las siguientes recomendaciones: supresión de las letras $h, v$ y $z$, porque no representaban sonidos en el español de América; supresión de la $x$, que puede ser reemplazada por cs o gs; supresión de la $u$ muda de las combinaciones gue, gui, que, qui; sustitución de la y por la $i$ cuando esta letra representa la vocal, etc. La Facultad de Humanidades aprobó, en parte, las recomendaciones de Sarmiento, y estuvieron en boga en Chile por algunos años. Después de abandonar el sistema de Sarmiento, la Facultad adoptó las reglas ortográficas contenidas en la famosa Gramática de Bello ${ }^{39}$. La Memoria sobre Ortografía americana y un gran número de artículos sobre la Ortografía escritos por Sarmiento se encuentran en varios tomos de las Obras completas de Sarmiento. Algunas citas de Lastarria y de Sarmiento, que se encuentran en nuestro ensayo, reflejan las reformas ortográficas o de Sarmiento o de Bello. El uso u omisión del acento ortográfico refleja las reglas de la Academia Española de esa época.

Con ocasión del primer aniversario de la Universidad de Chile (1844), el Rector, Andrés Bello, le encargó a Lastarria (miembro de dos Facultades de la Universidad) que presentara la primera memoria histórica. E1 trabajo que presentó Lastarria, y que provocó gran controversia, fue $I n$ vestigaciones sobre la influencia social de la conquista i del sistema co-

${ }^{38}$ Armando Donoso, «Sarmiento y Lastarria», en Revista chilena, t. X (1920), p. 23.

${ }^{39}$ Guerra, op. cit., pp. 87-89. 
lonial de los españoles en Chile ${ }^{40}$. Esta memoria es una continuación del discurso del 3 de mayo de 1842 ante la recién fundada «Sociedad Literaria», y establece el método de escribir la historia empleada por Lastarria en obras históricas suyas, tales como Bosquejo histórico de la Constitución del Gobierno de Chile durante el primer período de la revolución, desde 1810 hasta 1814 (1847), Historia constitucional del medio siglo (1853) y La América (1867). En las Investigaciones, Lastarria pide a los chilenos que rechacen el pasado colonial español. Según él, la historia colonial de Chile es la historia de tres siglos de ignorancia y esclavitud. España trasplantó a sus colonias americanas todos los vicios de su absurdo sistema de gobierno. España había sujetado a los indígenas a la más humillante y grosera servidumbre. Se anulaba la educación intelectual y moral. La codicia despertaba en los españoles deseos inmorales, intereses criminales y la corrupción.

Bello, que invitó a Lastarria a que hiciera su memoria histórica, se vio obligado a comentarla. Alababa las Investigaciones por «la copia de ideas, la superioridad filosófica, el órden lúcido, el estilo vigoroso, pintoresco i generalmente correcto con que está escrita» y veía en la obra «una muestra brillante de lo que prometen los talentos i luces del señor Lastarria a su patria i a la Universidad de que es miembro». Pero Bello no podía aceptar la filosofía de la historia propuesta por Lastarria. Según él, había que basar la historia sobre los hechos y era preciso acumular datos con paciencia y por muchos años. «La injusticia, la atrocidad, la perfidia en la guerra - decía Bello - no han sido de los españoles solos, sino de todas las razas, de todos los siglos.» Por eso no podemos acusar a la nación española ni a ninguna nación, sino a la naturaleza del hombre. El retrato de España en el Nuevo Mundo presentado por Lastarria era 'inexacto' ${ }^{41}$. Las Investigaciones de Lastarria y el Comentario de Bello iniciaron los debates en Chile sobre métodos de escribir la historia: Lastarria representando la filosofía de la historia, y Bello, el método narrativo ${ }^{42}$.

Sarmiento escribió un comentario sobre las Investigaciones de Las-

${ }^{40}$ Las Investigaciones de Lastarria están en las Obras completas de Lastarria, t. VII, pp. 17-143; en su Miscelánea histórica i literaria, t. I, pp. 3-136, y en la antología de Durán Cerda, t. I, pp. 33-65.

${ }^{41}$ Andrés Bello, «Comentario a las "Investigaciones" sobre la influencia social de la conquista i del sistema colonial de los españoles en Chile por don José Victorino Lastarria», en El Araucano (1844). Este comentario de Bello también está en el tomo VII (pp. 71-88) de sus Obras completas (Santiago de Chile, 1884). Está reimpreso en la antología de Durán Cerda, t. I, pp. 87-102. Véase también Sacks, op. cit., pp. 167-168.

${ }^{42}$ Allen Woll, A Functional Past: The Uses of History in Nineteenth-Century Chile (Baton Rouge: Louisiana State University Press, 1982), cap. II. 
tarria. Según él, el libro estaba «lleno de lucidez y concebido en un lenguaje fácil y depurado, las ideas que contiene son el fruto de una meditación y estudio tan completo como es posible hacerlo con la escasez de materiales de que puede echarse mano para asunto tan arduo». Sin embargo, Sarmiento no estaba de acuerdo con Lastarria en lo que respecta al tratamiento de los indígenas por los españoles. $\mathrm{Y}$ así dijo:

Es preciso que seamos justos con los españoles; al exterminar a un pueblo salvaje cuyo territorio iban a ocupar, hacían simplemente lo que todos los pueblos civilizados hacen con los salvajes, lo que la colonia efectúa deliberada o indeliberadamente con los indígenas; absorbe, destruye, extermina... Puede ser muy injusto exterminar salvajes..., pero gracias a esta injusticia la América, en lugar de permanecer abandonada a los salvajes, incapaces de progreso, está ocupada hoy por la raza cat1cásica, la más perfecta, la más inteligente, la más bella y la más progresiva de las que pueblan la tierra...; las razas fuertes exterminan a las débiles... Esto es providencial y útil, sublime y grande... Creemos, pues, que no debieran ya nuestros escritores insistir sobre la crueldad de los españoles para con los salvajes de la América, ahora como entonces, nuestros enemigos de raza, de color, de tendencias, de civilización... ${ }^{43}$

El anti-indigenismo de Sarmiento es muy conocido. Sarmiento creía que el indio era una causa fundamental del atraso de Hispanoamérica, y esta creencia es evidente en una obra suya como Conflictos y armonias de las razas en América (1883), publicada cinco años antes de su muerte ${ }^{44}$. Aunque se puede decir que las ideas racistas eran comunes en la época de Sarmiento, Lastarria no las tenía. En una de sus novelitas, titulada Una hija (1881), Lastarria defiende a los negros contra los blancos ${ }^{45}$.

Sarmiento, como Lastarria, criticaba la herencia española en el Nuevo Mundo. Dirigiéndose a sus compatriotas, Sarmiento decía: «iNo os riáis, pues, pueblos hispanoamericanos, al ver tanta degradación! iMirad que sois españoles y la Inquisición educó así a la España! iEsta enfermedad la traemos en la sangre! ${ }^{46}$. $Y$ en Conflictos y armonías de las razas en

${ }^{43}$ D. F. Sarmiento, «Investigaciones sobre el sistema colonial de los españoles por J. V. Lastarria», en El Progreso (1844). Este comentario también está en el tomo II (pp. 215-222) de sus Obras completas.

${ }_{44}$ Véase Jaime Alazraki, «El indigenismo de Martí y el anti-indigenismo de Sarmiento», en Cuadernos Americanos, año XXIV, t. CXL, núm. 3 (mayo-junio 1965), pp. 135-137. Y el trabajo de Daniel Zalazar en Revista Iberoamericana, 127 (abriljunio 1984), que es favorable a Sarmiento.

${ }_{45}$ Véase Obras completas de don J. V. Lastarria, t. XII, pp. 399-458.

${ }^{46}$ Sarmiento, Facundo, edición crítica de Alberto Palcos (Buenos Aires: Ministerio de Educación y Justicia, 1962), p. 135. 
América recalca: «Descartes puso por fundamento de la filosofía, no dando por probada la existencia de nada: 'Pienso; luego existo'. Un español o un americano del siglo xvi debió decir con más verdad: 'existo, luego no pienso'» ${ }^{47}$.

En una larga carta de Sarmiento a Lastarria, ctando el argentino estaba en Madrid (15 noviembre 1846), Sarmiento ofrece sus observaciones e impresiones de España y los españoles:

El arado romano es el único implemento de agricultura conocido... No se estudian las ciencias naturales... Ningún español ha hecho estudios geológicos sobre el suelo de la España... No se estudia el griego, porque el clero no tenía afición a este idioma... Cien ciudades interiores, Toledo, Burgos, son montones de ruinas... Ninguna ciudad nueva se ha levantado... Ninguna industria se ha introducido en tres siglos... No hay caminos, sino dos grandes vías... No hay educación popular... Si yo hubiera viajado en España en el siglo XvI, mis ojos no habrían visto otra cosa que lo que ahora ven ${ }^{48}$.

Sarmiento tuvo opinión desfavorable sobre la historia y cultura de España, y explicó las tiranías en su país por la pobreza, la ignorancia y el fanatismo, reliquias de la tradición colonial española ${ }^{49}$.

Sobre las relaciones entre Sarmiento y Lastarria, escribió Armando Donoso:

Sus ideas, afines en instrucción pública, en lo que toca a las libertades políticas, en letras y en filosofía, debieron mantener unidos siempre a estos dos hombres únicos en la cultura americana; pero se interpuso entre ambos la amistad de Montt, que fue pródiga en sus dones con Sarmiento, mientras Lastarria se vio obligado a renunciar a ella primero y a combatirla luego ${ }^{50}$.

Montt y Lastarria eran amigos de la infancia y de colegio, y cuando Montt fue Rector del Instituto Nacional (1835-1840), nombró a Lastarria profesor de Legislación y Derecho de gentes. Montt dejó el rectorado en 1840 y aceptó el puesto de Ministro de Justicia e Instrucción Pública. En 1843, Lastarria aceptó el puesto de subsecretario del Ministerio del Interior, a que había sido llamado por el Ministro del Interior, Ramón de

${ }^{47}$ Obras completas de Sarmiento, t. XXXVII, p. 125.

${ }^{48}$ Viajes por Europa, Africa y América, en Obras completas de Sarmiento, t. V, pp. 139-160.

${ }^{49}$ Ricardo Rojas, El profeta de la pampa. Vida de Sarmiento (Buenos Aires: Editorial Losada, 1945), cap. XXI.

${ }^{50}$ Sarmiento en el destierro, p. 44. 
Irarrázaval, pelucón como Montt, pero «en cuyo peluconismo creía [Lastarria] descubrir un espíritu más liberal, más franco y conciliador que en los demás políticos de su escuela». Había un sordo antagonismo entre Irarrázaval y Montt, conflicto que terminó con la retirada de Irarrázaval. Montt lo reemplazó como Ministro del Interior, y se hizo jefe inmediato de Lastarria. Los antiguos amigos se convirtieron en enemigos ideológicos. La personalidad de Montt era autoritaria e inflexible. Como ha dicho Melfi: «En Montt no hubo adolescencia... En Montt no hubo goces... un ser prematuramente grave y serio... un hombre ferozmente combatido" ${ }^{51}$. Montt y Lastarria no se llevaban bien, y Lastarria abandonó su puesto en 1844, después de haber servido en él durante dieciséis meses ${ }^{52}$. Galdames ha contrastado a los dos hombres:

Miéntras para Montt lo primero era el órden, para Lastarria lo primero era la libertad. Ambos querian lo uno i lo otro, pero miéntras aquel queria la libertad en el órden, éste queria el órden en la libertad... Amigo de éste [Montt] i compañero en el profesorado, poco a poco [Lastarria] habia ido tomándole distancia, a consecuencia de la misma diversidad de sus principios, hasta hallarse en abierta contradicción ${ }^{53}$.

Sarmiento abandonó su puesto como redactor de El Mercurio el 25 de agosto de 1842. Algunos miembros del Partido Conservador fundaron El Progreso, que se publicó por primera vez el 10 de noviembre de 1842 . El Progreso fue el primer diario de Santiago, y Sarmiento lo redactó desde su fundación hasta mayo de 1843, y más tarde, desde fines de marzo de 1844 hasta principios de octubre de 1845. Durante estas dos épocas, la redacción de El Progreso fue el órgano semioficial del Partido Pelucón, y especialmente del ministro don Manuel Montt, que llegó a ser una figura política destacada entre los conservadores.

Poco después de la reaparición de Sarmiento como redactor y sostenedor de la política de Montt en El Progreso, se fundó en Santiago el diario El Siglo, cuyo redactor fue Juan Nepomuceno Espejo, en el cual colaboraron Lastarria, el coronel Godoy y otros. El Siglo había de servir de órgano a las ideas de Irarrázaval, que representaba una tendencia del partido imperante distinta a la tendencia representada por Montt. Se entabló una violenta controversia entre los dos diarios, Sarmiento iniciando la lucha. El argentino se convirtió en el blanco de ataques de parte

${ }^{51}$ Domingo Melfi, «Montt y Sarmiento», en Atenea, año XIV, t. XL, núm. 149 (noviembre 1937), pp. 183-194.

${ }_{52}$ Justo y Domingo Arteaga Alemparte, Los Constituyentes de 1870 (Santiago de Chile: Imprenta Barcelona, 1910), pp. 33-34.

${ }^{53}$ Luis Galdames, El decenio de Montt (Santiago de Chile, 1901), p. 213. 
de colaboradores de $E l$ Siglo, y quien atacó con mucha crueldad a Sarmiento fue el coronel Godoy. Sarmiento hizo responsable de esos ataques a su amigo Lastarria, y sus relaciones sufrieron una ruptura ${ }^{54}$.

El 28 de abril de 1844, Sarmiento escribió la siguiente carta a Lastarria:

Señor Dn. Victorino Lastarria.

Mui señor mío

No deseo esplicaciones de parte de V. i no estoi dispuesto a darlas tampoco. Como V. no a podido estorbar qe el Siglo me injurie, me echa en cara $\mathrm{q}^{\mathrm{e}}$ soi asalariado, $\mathrm{i}$ estranjero, no obstante abermelo prometido, i como se qien escribe en el, si no $q^{e} V$. es el dueño de la imprenta para su negocio, y para su elevación política; me dirijiré a $V$. siempre $q^{e}$ qiera desbaratar las ipócritas ataqes de su diario, i descubriré al público los motivos puramente personales $\mathrm{q}^{\mathrm{e}} \mathrm{V}$. tenga para llevar un diario.

Esta prevención le indicará a $\mathbb{V}$. qe toda armonía e inteligencia entre ambos a cesado, $\mathrm{i} \mathrm{q}^{\mathrm{c}}$ no qiero ser el juguete de $\mathrm{V}$. o sus órganos.

Qedo de V.

Abril 22

Sarmiento

Al pie de la carta de Sarmiento, Lastarria escribió su contestación:

Sr. Sarmiento

Acuso recibo de la declaración de guerra $q^{e} V$. me ace, previniéndole $\mathrm{q}^{\mathrm{e}}$ no sufriré de $\mathrm{V}$. ofensa ninguna contra mi onor.

Lastarria ${ }^{55}$.

Con el tiempo, Sarmiento y Lastarria reanudaron su amistad. Montt era amigo y protector de Sarmiento, y el argentino continuaba sosteniendo la carrera política de Montt, sobre todo en la elección de Montt a la presidencia de Chile (1851-1861). Hasta el fin de su vida, los mejores amigos de Sarmiento en Chile fueron Manuel Montt y José Victorino Lastarria, dos hombres con sentimientos recíprocos de antagonismo.

Hay que notar diferencias ideológicas entre Sarmiento y Lastarria para comprender la cuestión de Manuel Montt. Lastarria era liberal doctrinario e intransigente; Sarmiento no lo era. Lastarria estaba embriagado con las ideas de la libertad y la democracia. De Sarmiento ha dicho Martínez Estrada: «Tenía el impulso del líder, el arrebato del profeta, pero le faltaba la fe en el pueblo... Sarmiento se hubiera hecho quemar por sus ideas,

${ }^{54}$ Guerra, op. cit., pp. 81-82, 92-93.

${ }_{55}$ María Luisa del Pino de Carbone, Correspondencia entre Sarmiento y Lastarria: 1844-1888 (Buenos Aires: Artes Gráficas Bartolomé U. Chiesino, 1954), pp. 25-26. 
pero por amor al pueblo no habría dado una gota de su sangre. ... Amaba y compadecía al individuo infeliz, pero la infelicidad colectiva lo afectaba en sus ideas más que en su sensibilidad» ${ }^{56}$. Verdevoye comenta la actitud de Sarmiento para con el pueblo: «Il se méfie des masses ignares, toujours prêtes à suivre celui qui les flatte... Sarmiento est en principe démocrate. Souvent il parle de la souveraineté du peuple comme d'un principe indiscutable. Il juge toutefois que le moment n'est pas venu de l'appliquer» ${ }^{57}$.

En una carta de Sarmiento a Lastarria, escrita el 2 de junio de 1874, el argentino (que es presidente de su país) reconoce que él y su amigo chileno no tienen el mismo concepto del liberalismo:

Señor D. Victorino Lastarria

Buenos Aires, Junio 2/74

Mi querido tuerto.

Estais contento de mi gobierno?

Os envío mi último Mensaje para que os regocijeis de ver que ha sido feliz el ensayo de un gobierno libre, moderado por la fuerza de las armas que el pueblo (estilo pipiolo) puso en mis augustas manos.

Soy, lo sabeis, menos liberal que vos, y nos hemos batido en su tiempo, quiza sin comprendernos, como sucede siempre à los combatientes. Yo estaba con mi amigo Montt, en cuanto a establecer gobierno, con vos en cuanto a dejar libre la acción (al pueblo). Mi teoria la puse en práctica en estos cinco años, y en uno y otro sentido, Montt y vos habeis ganado el pleito... ${ }^{58}$

En la Argentina solían decirle achilenado a Sarmiento. Una vez contestó en El Nacional (1881): «Soy achilenado como soy yankificado, por largos años de residencia y estudio de sus diversas instituciones» ${ }^{59}$. Manuel Montt, durante su presidencia de Chile, invitó a Sarmiento a que tomara ciudadanía chilena, pero el argentino no aceptó ${ }^{60}$.

Lastarria pensaba en términos continentales y gozaba de prestigio continental. Sin embargo, identificado con la vida cultural y política de

${ }^{56}$ Ezequiel Martínez Estrada, Sarmiento (Buenos Aires: Editorial Sudamericana), p. 141.

57 Paul Verdevoye, Domingo Faustino Sarmiento. Educateur et publiciste (entre 1839 et 1852) (Paris: Institut des Hautes Études de l'Amérique Latine, 1963), pp. 401-402.

${ }^{58}$ Pino de Carbone, pp. 81-82.

${ }^{59}$ Obras completas de Sarmiento, t. LII, p. 283. Citado por Ricardo Rojas, El profeta de la pampa, p. 673.

${ }^{60}$ Obras completas de Sarmiento, t. LII, p. 283. 
Chile, nunca se olvidó de que era chileno. A pesar de sus muchos años en Chile y sus contribuciones importantes a la vida cultural, educacional y política de ese país, Sarmiento nunca se olvidó de que era argentino.

Cuando Sarmiento recibió noticias de la muerte de su amigo Lastarria, escribió una carta a un hijo de don Victorino:

\section{Señor D. Demetrio Lastarria}

Asunción, Julio 10 de 1888

Mi estimado señor y amigo:

La noticia de la muerte de mi querido amigo Dn. Victorino me llega por los diarios de B. Aires, y no quiero que la distancia sea obstáculo para que me asocie en el pesar a su familia y a todos los que lo estimaban como merecía.

Esperimenté todo jénero de contrariedades, a veces repulsiones, tuve amigos sinceros o de circunstancias; pero entre todos ellos se distinguía Lastarria, por el afecto, por la deferencia, por una cierta aprobación tácita, y sobre todo por la protección que me dispensaba, cuando habría de serme necesaria. Diría que Lastarria era liberal en lo más íntimo de su significado... ${ }^{\text {b1 }}$

El chileno Lastarria murió el 14 de junio de 1888. A los tres meses, el 11 de septiembre, falleció en Asunción el argentino achilenado.

\footnotetext{
${ }^{61}$ Pino de Carbone, p. 163.
} 